\title{
Global knockdown of glutamate decarboxylase 67 elicits emotional abnormality in mice
}

\author{
Shigeo Miyata ${ }^{\text {** }}$, Toshikazu Kakizaki ${ }^{1}$, Kazuyuki Fujihara ${ }^{1}$, Hideru Obinata² ${ }^{2}$ Touko Hirano², Junichi Nakai ${ }^{3}$, \\ Mika Tanaka ${ }^{4}$, Shigeyoshi Itohara ${ }^{4}$, Masahiko Watanabe ${ }^{5}$, Kenji F. Tanaka ${ }^{6}$, Manabu Abe ${ }^{7}$, Kenji Sakimura ${ }^{7}$ \\ and Yuchio Yanagawa ${ }^{1 *}$
}

\begin{abstract}
Reduced expression of glutamate decarboxylase 67 (GAD67), encoded by the Gad1 gene, is a consistent finding in postmortem brains of patients with several psychiatric disorders, including schizophrenia, bipolar disorder and major depressive disorder. The dysfunction of GAD67 in the brain is implicated in the pathophysiology of these psychiatric disorders; however, the neurobiological consequences of GAD67 dysfunction in mature brains are not fully understood because the homozygous Gad1 knockout is lethal in newborn mice. We hypothesized that the tetracyclinecontrolled gene expression/suppression system could be applied to develop global GAD67 knockdown mice that would survive into adulthood. In addition, GAD67 knockdown mice would provide new insights into the neurobiological impact of GAD67 dysfunction. Here, we developed Gad $7^{\text {TA/STOP-tetO }}$ biallelic knock-in mice using Gad $7^{\text {STOP-tetO }}$ and Gad ${ }^{\text {TA }}$ knock-in mice, and compared them with Gad1+/+ mice. The expression level of GAD67 protein in brains of Gad ${ }^{\text {TAASTOP-tetO }}$ mice treated with doxycycline (Dox) was decreased by approximately $90 \%$. The GABA content was also decreased in the brains of Dox-treated Gad ${ }^{\text {TAASTOP-tetO }}$ mice. In the open-field test, Dox-treated Gad ${ }^{\text {TAASTOP-tetO }}$ mice exhibited hyper-locomotor activity and decreased duration spent in the center region. In addition, acoustic startle responses were impaired in Dox-treated Gad ${ }^{\text {tA/STOP-tetO }}$ mice. These results suggest that global reduction in GAD67 elicits emotional abnormalities in mice. These GAD67 knockdown mice will be useful for elucidating the neurobiological mechanisms of emotional abnormalities, such as anxiety symptoms associated with psychiatric disorders.
\end{abstract}

Keywords: Animal model, Auditory function, Behavior, GABA, Glutamate decarboxylase, Knockdown mice, Tetracycline-controlled gene expression

\section{Introduction}

$\gamma$-Aminobutyric acid (GABA), a major inhibitory neurotransmitter, regulates a variety of biological functions. GABA is synthesized from glutamate by glutamate decarboxylase (GAD) existing two isoforms with different molecular weights, $67 \mathrm{kDa}$ (GAD67) and $65 \mathrm{kDa}$ (GAD65), which are independently encoded by the Gad1

\footnotetext{
*Correspondence: s_miyata@gunma-u.ac.jp; yuchio@gunma-u.ac.jp ${ }^{1}$ Department of Genetic and Behavioral Neuroscience, Gunma University Graduate School of Medicine, Maebashi 371-8511, Japan
}

Full list of author information is available at the end of the article and Gad2 genes, respectively [1, 2]. Since GAD67 and GAD65 proteins have different subcellular distributions and a cofactor association [3-6], the physiological roles of GAD67 and GAD65 may be different in the brain.

Decreased expression of the full-length GAD1 transcript and GAD67 protein is one of the most consistent findings in the brains of subjects with several psychiatric disorders, including schizophrenia, bipolar disorder and major depressive disorder [7-12]. Alternative splicing of GAD1 and the epigenetic state may play roles in brain development and the risk of schizophrenia [12]. original author(s) and the source, provide a link to the Creative Commons licence, and indicate if changes were made. The images or other third party material in this article are included in the article's Creative Commons licence, unless indicated otherwise in a credit line to the material. If material is not included in the article's Creative Commons licence and your intended use is not permitted by statutory regulation or exceeds the permitted use, you will need to obtain permission directly from the copyright holder. To view a copy of this licence, visit http://creativecommons.org/licenses/by/4.0/. The Creative Commons Public Domain Dedication waiver (http://creativeco mmons.org/publicdomain/zero/1.0/) applies to the data made available in this article, unless otherwise stated in a credit line to the data. 
Recent studies with whole exome sequencing of schizophrenic patients identified missense mutation mapping at the GAD1 gene, which caused a reduction in GAD67 enzymatic activity by $30 \%$ due to impaired homodimerization $[13,14]$. Therefore, the functional impairment of GAD67 associated with genetic mutations is involved in the neurobiological mechanisms of several psychiatric disorders. To elucidate the physiological roles of GAD67 in mature brains, a study using transgenic animals with reduced GAD67 expression would be helpful. Because homozygous Gad1 knockout $\left(\mathrm{Gad1}^{-/-}\right)$is lethal in newborn mice [15], conditional Gad1 $1^{-1-}$ mice generated with a Cre-loxP strategy have often been used for neurobiological studies [16-20]. These studies have provided much information about the function of GAD67 in targeted cells. However, behavioral and neurochemical consequences of the global dysfunction of GAD67 in mature brains are not fully understood. Several studies have been performed to investigate GAD67 function using mice with GAD67 haplodeficiency; however, physiological changes, such as GABA reduction in the brain and behavioral abnormalities, were mild in those mice [15, 21-24].

The tetracycline-controlled gene expression/suppression system allows reduction in a gene of interest by administration of antibiotic tetracyclines and its derivative doxycycline (Dox) [25]. This system requires two distinct transgenic mice: one has a cell type-specific promoter driving a tetracycline-controlled transcriptional activator (tTA)-expressing allele, and the other has a tetracycline operator site (tetO) binding to tTA and driving the expression of the gene of interest. By crossing them, a biallelic knock-in mouse (tTA/tetO) can be obtained with a tTA-mediated gene induction system, which can be turned off by the administration of Dox.

We hypothesized that the tetracycline-controlled gene expression/suppression system could be applied to generate transgenic mice able to postnatally knockdown GAD67. In brief, two knock-in mice were generated: (1) Gad1 ${ }^{\mathrm{STOP}-\text { tetO }}$ knock-in mice, which were generated by inserting the tetO sequence following the STOP sequence upstream of the Gad1 translation initiation site (Fig. 1a), and (2) Gad1 ${ }^{\text {tTA }}$ knock-in mice [26], which express tTA proteins under the control of an endogenous Gad1 promoter (Fig. 1b). The Gad1 $1^{\mathrm{tA} /}$ STOP-tetO mice can produce GAD67 protein (Fig. 1c) and survive into adulthood. In addition, the expression of GAD67 protein in the Gad1 ${ }^{\text {tTA/STOP-tetO }}$ mice is suppressed by treatment with Dox (Fig. 1d). Therefore, Dox-treated Gad1 ${ }^{\text {tTA/STOP-tetO }}$ mice can be used as GAD67 knockdown mice for studying the behavioral

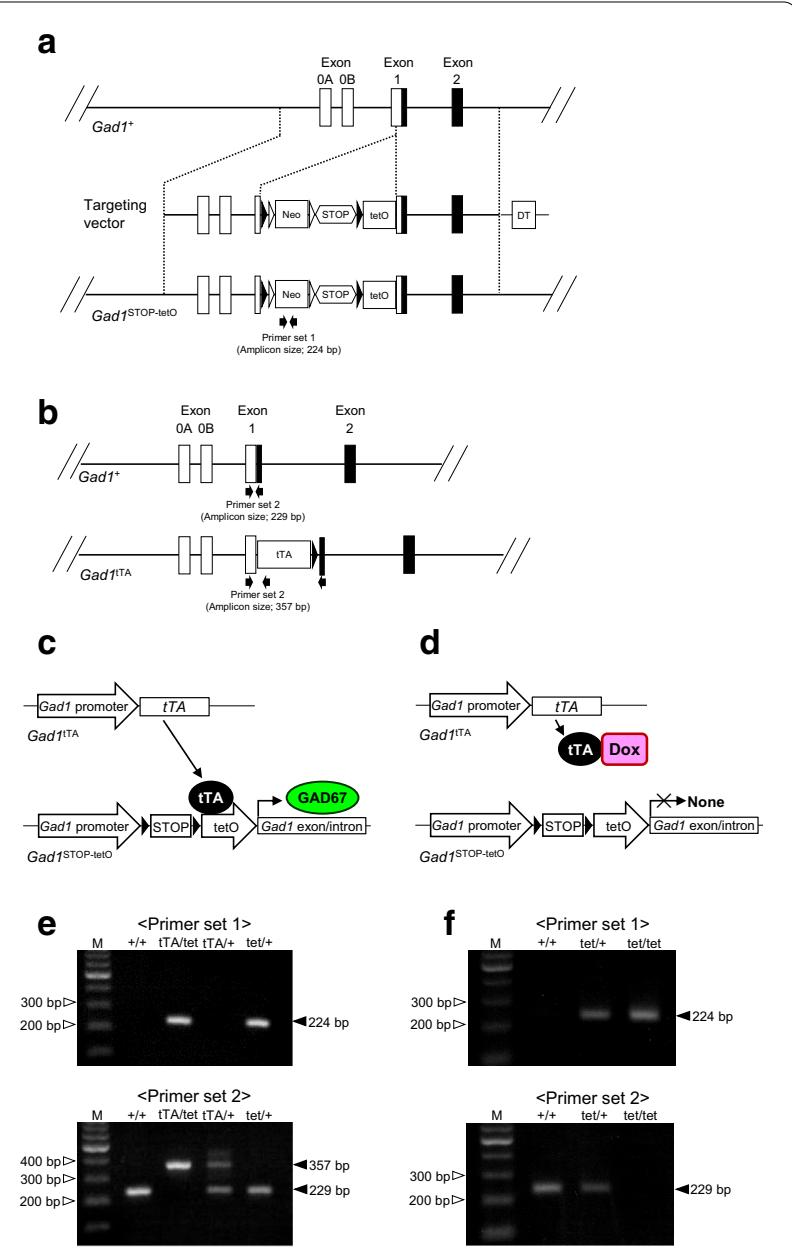

Fig. 1 Doxycycline (Dox)-regulated Gad1 suppression system. a Generation of Gad $1^{\text {STOP-tetO }}$ knock-in mice. Schematic diagram depicting Gad1 genomic DNA (Gad1 ${ }^{+}$), targeting vector, and Gad1 genomic DNA inserted into the Neo-STOP-tetO cassette (Gad1 ${ }^{\text {STOP- }}$ tetO). Arrows indicate the PCR primers (Primer set 1). b Schematic representation of Gad1 genomic DNA $\left(\mathrm{Gadl}^{+}\right)$and DNA containing the tetracycline-controlled transactivator (tTA) gene $\left(\mathrm{Gad}{ }^{\mathrm{TA}}\right.$ ). Arrows indicate the PCR primers (Primer set 2). $\mathbf{c}, \mathbf{d}$ Schematic diagram of the Dox-regulated Gad1 suppression system in Gad $1^{\text {TANSTOP-tetO }}$ mice. Before Dox treatment, tTA binds to the tetracycline operator site (tetO) and promotes Gad1 transcription and GAD67 production (c). Dox treatment interferes with tTA binding to tetO and suppresses Gad1 transcription (d). e, $\mathbf{f}$ PCR genotyping. Representative results of PCR genotyping for Gad $1^{\text {tAASTOP-tetO }}$ mice $(\mathbf{e})$, Gad $1^{\text {STOP-tetO/STOP-tetO }}$ mice (f) and their littermates. M; 100-bp size marker, +/+; Gad $1^{+/+}$,

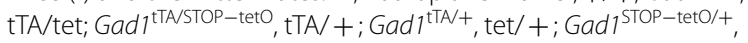
tet/tet; Gad1 ${ }^{\text {STOP-tetO/STOP-tetO }}$

and neurochemical consequences of the global loss of GAD67 in mature brains.

The major aim of this study was to examine the phenotypes of mice with GAD67 suppression at adult stage. In this study, we successfully developed Gad1 ${ }^{\text {STOP-tetO }}$ knock-in mice and the subsequent $G a d 1^{\mathrm{tTA} / \mathrm{STOP}-\text { tetO }}$ 
mice. Herein, we report the behavioral abnormalities elicited by the global knockdown of GAD67 in mice.

\section{Methods}

\section{Ethics}

This study was performed in accordance with the Guidelines for Animal Experimentation at Gunma University Graduate School of Medicine and was approved by the Gunma University Ethics Committee (Permit number: 14-006 and 19-009). Every effort was made to minimize the number of animals used and their suffering.

\section{Experimental design}

We first generated Gad1 ${ }^{\text {STOP-tetO }}$ knock-in mice and assessed the Gad1 knockout phenotypes (GAD67 deletion, neonatal death and cleft palate) of homozygous Gad1 ${ }^{\text {STOP-tetO/STOP-tetO }}$ mice to confirm the elimination of Gad1 gene function by inserting the Neo-STOPtetO cassette. We then crossed heterozygous $\mathrm{Gad1}^{\mathrm{tTA} /+}$ and $\mathrm{Gad} 1^{\mathrm{STOP}-\mathrm{tetO} /+}$ mice to obtain $\mathrm{Gad} 1^{\mathrm{tTA} / \mathrm{STOP}-\text { tetO }}$ mice and confirmed tTA-mediated GAD67 expression. Afterward, we evaluated whether tTA-mediated GAD67 expression was suppressed by treatment with Dox. It has been reported that GAD67 haplodeficient mice demonstrate an approximately $40 \%$ reduction in GAD67 protein in the brain compared with wild-type mice [27]. Therefore, we judged that GAD67 knockdown mice were successfully developed when the expression level of GAD67 protein in the brain was reduced by more than $40 \%$. These experiments were performed in mice of both sexes.

In the behavioral tests, male mice were only used. We prepared two independent cohorts comparing $\mathrm{Gad1}^{+/+}$ mice and Gad1 $1^{\mathrm{tTA} / \mathrm{STOP}-\mathrm{tetO}}$ mice at the ages of 8 to 10 weeks. One cohort was used for assessing the body weights, motor coordination performance, and GABA and glutamate contents in their brains. The body weights and motor coordination performance of the mice were measured 3 weeks after starting Dox treatment. Immediately after the motor coordination test, the mice were killed by decapitation, and the frontal cortex (FCX), hippocampus (HIP) and cerebellum (CER) were quickly dissected. The collected tissues were immediately frozen in liquid nitrogen and stored at $-80^{\circ} \mathrm{C}$ until use. The frozen tissues were used for measuring GABA and glutamate contents. Another cohort was used for the open-field test and PPI test. Three weeks after treatment with Dox, the open-field test was conducted. After testing, the mice were returned to their home cage, and treatment with Dox was continued. Two days after the open-field test, the acoustic startle responses and prepulse inhibition (PPI) responses were assessed in the mice.

\section{Animals}

To generate Gad1 ${ }^{\text {STOP-tetO }}$ knock-in mice, we constructed the Gad1 targeting vector by linking the following elements in tandem: the 4.7-kb $5^{\prime}$-homology arm, 3.4-kb Neo-STOP-tetO cassette [28], 5.9-kb 3'-homology arm, and the $\mathrm{MC1}$ promoter-driven diphtheria toxin A subunit gene (DT) (Fig. 1a). The Neo-STOP-tetO cassette comprised the 1.7-kb PGK-Neo cassette, a $1.3-\mathrm{kb}$ STOP sequence, and a $0.5-\mathrm{kb}$ tetO site. The targeting vector was designed to insert the Neo-STOP-tetO cassette just upstream of the Gad1 translation initiation site. We used B6-derived embryonic cells for homologous recombination. From 179 G418-resistant clones, we obtained 46 recombinant clones. Germline-transmitted offspring were established as $G a d 1^{\mathrm{STOP}-\text { tetO }}$ knock-in mice (Fig. 1a).

The generation of $\operatorname{Gadl}^{\mathrm{tTA}}$ knock-in mice has already been described [26]. In these mice, the $t T A 2 \mathrm{cDNA}$ followed by the SV40 polyadenylation signal was inserted into exon 1 of the Gad1 gene in frame with the translation initiation codon, and the tTA protein was expressed under the control of an endogenous Gad1 promoter (Fig. 1b).

Heterozygous mice carrying one STOP-tetO allele (Gad1 ${ }^{\text {STOP-tetO/+ }}$ mice) were crossed with heterozygous mice carrying one tTA allele ( $\operatorname{Gad} 1^{\mathrm{tTA} /+}$ mice) to obtain four genotypes: $\mathrm{Gad1}^{+/+}, \mathrm{Gad1}^{\mathrm{tTA} /+}, \mathrm{Gad1}^{\mathrm{STOP}-\mathrm{tetO} /+}$ and $G a d 1^{\text {tTA/STOP-tetO }}$ mice. To prevent the expression of GAD67 protein, we administered $100 \mathrm{mg}$ of Dox per $\mathrm{kg}$ of regular mouse chow CE-2 (CLEA Japan, Inc.).

The animals were housed at 2-3 mice per cage $(16.5 \times 27 \times 12.5(\mathrm{H}) \mathrm{cm})$ and had free access to food and water. The animal rooms for breeding and experiments were maintained at $22 \pm 3{ }^{\circ} \mathrm{C}$ with a 12-h light-dark cycle (lights on at 6:00, lights off at 18:00).

\section{Genotyping}

Genotyping of the transgenic mice was performed by PCR using tail genomic DNA with SapphireAmp Fast PCR master mix (Takara Bio Inc., Japan) and the specific primer sets. Primer set 1 determined the existence of the $\mathrm{Neo}$ allele (Fig. 1a); the sequences were Neo-F, $5^{\prime}$-CAG CTGTGCTCGACGTTGTC-3' and Neo-R, 5' ${ }^{\prime}$-AAGACC GGCTTCCATCCGAG- $3^{\prime}$. Primer set 2 determined the existence of the Gad1 and $t T A$-inserted Gad1 alleles (Fig. 1b); the sequences were Gad1-F, 5'-TGGTCTCCC TTCTGTCTCCGA-3', Gad1-R, 5'-TGTAGGGCGCAG GTTGGTAG- ${ }^{\prime}$, and tTA-R, 5'-GGGCAAAAGTGA GTATGGTGCC-3'. After amplification, $5 \mu \mathrm{L}$ of each reaction mixture and a size marker (Loading Quick 100 bp DNA Ladder, TOYOBO Co. Ltd, Osaka, Japan) were analyzed by $2 \%$ agarose gel electrophoresis, and the 
bands were then visualized by ethidium bromide staining. The lengths of the amplified DNA fragments were 224 bp (Neo allele), $229 \mathrm{bp}$ ( Gad1 allele) and $357 \mathrm{bp}$ ( $t T A-$ inserted Gad1 allele) (Fig. 1e, f).

\section{Palate formation}

Mouse neonates were killed by decapitation, and the lower jaw was removed. The cleft palate of the mouse was determined under a stereoscopic microscope.

\section{Immunoblot analysis}

The mice were killed by decapitation. The brain hemispheres of neonates and the FCX, HIP and CER of adult mice were quickly dissected on an ice-cold stainless plate. The tissues were immediately frozen in liquid nitrogen and stored at $-80{ }^{\circ} \mathrm{C}$ until use. The frozen tissues were homogenized in ice-cold buffered sucrose $(0.32 \mathrm{M})$ solution containing $20 \mathrm{mM}$ Tris- $\mathrm{HCl}(\mathrm{pH}$ 7.5) and protease inhibitor cocktail (P8340, Sigma-Aldrich, Inc.). The homogenates were centrifuged at $1000 \times g$ for $10 \mathrm{~min}$ at $4{ }^{\circ} \mathrm{C}$, and the supernatants were collected as the protein samples. The protein concentrations were determined using a TaKaRa BCA Protein Assay Kit (T9300A, Takara Bio Inc., Japan).

The protein samples were diluted with electrophoresis sample buffer. Proteins $(1.5 \mu \mathrm{g})$ were separated by 8\% SDS-polyacrylamide gels and transferred to a PVDF membrane. Blots were probed with respective antibodies to GAD65/67 (1:1000, rabbit polyclonal antibody) [29] and GAD67 (1:1000, mouse monoclonal antibody, Millipore, Code No. MAB5406). Immunoblots were developed using horseradish peroxidase-conjugated secondary antibodies (GE Healthcare) and then detected with chemiluminescence reagents (ECL prime, GE Healthcare) and visualized by the Light Capture AE-9672 (ATTO Co., Ltd.). After the detection of immunoblots, the blotting membranes were washed with PBS several times and reprobed with a mouse monoclonal antibody to $\beta$-actin $(1: 10,000$, Medical \& Biological Laboratories Co. Ltd., Code No. M177-3). The immunoblots of $\beta$-actin were developed and visualized by the same protocol described above. The density of the bands was determined using ImageJ software. The band densities of $\beta$-actin were used as the loading control. The relative expression level of GAD67 to $\beta$-actin was calculated and used for comparisons between the genotypes.

\section{Double-label immunofluorescence analysis}

Deeply anesthetized mice by continuous inhalation of isoflurane were fixed by perfusion with Mildform $10 \mathrm{~N}$ (containing 3.7-4.3 w/w\% formaldehyde; FUJIFILM Wako Pure Chemical Co., Osaka, Japan) through the left ventricle. The brain was removed and postfixed in
Mildform $10 \mathrm{~N}$ overnight at $4{ }^{\circ} \mathrm{C}$. The brain hemispheres were cut into $50-\mu \mathrm{m}$-thick sagittal sections by a vibrating blade tissue slicer (Neo-LinearSlicer MT, Dosaka EM Co., Ltd., Kyoto, Japan).

Free-floating immunostaining was performed by using a VECTOR M.O.M. ${ }^{\circledR}$ (Mouse on Mouse) Immunodetection Kit (BMK-2202, Vector Laboratories Inc., USA). The sections were incubated overnight at room temperature in the 1st primary antibodies against GAD67 (1:300, mouse monoclonal antibody, MAB5406, Millipore) and parvalbumin (PV) (1:300, guinea pig polyclonal antibody, PV-GP-Af1000, Frontier Institute Co. Ltd., Hokkaido, Japan) with the M.O.M. Blocking reagent after preincubation with $0.3 \%$ Triton X-100 in PBS. After rinsing, the sections were incubated in the M.O.M. Biothinylated Anti-Mouse IgG Reagent (1:300) with a secondary antibody (1:300, goat anti-guinea pig IgG conjugated with AlexaFluor488, A-11073, Invitrogen) for $30 \mathrm{~min}$ at room temperature. After rinsing, the sections were incubated in a solution containing Streptavidin-DyLight649 (1:50, SA-5649, Vector Lab.) and DAPI (1:500, D523, Dojindo Laboratories, Japan) for $30 \mathrm{~min}$ at room temperature. The stained sections were mounted on MAS-coated glass slides (Matsunami Glass Ind., Ltd., Osaka, Japan) with Fluoromount (K024, Diagnostic BioSystems, USA). Fluorescence images were captured with a fluorescence digital microscope (BZ-X810, Keyence, Osaka, Japan).

Three independent mice in the respective groups were assessed. The names of brain regions were referenced to the Allen Mouse Brain Atlas (https://alleninstitute.org/).

\section{Motor coordination test}

The performance of motor coordination in mice was tested by a rotarod apparatus (Ugo Basile, Comerio, Italy) according to a previous report [16]. Briefly, each mouse was placed in a separate lane of the apparatus on a rotating cylinder $(3 \mathrm{~cm}$ diameter) at 20 rounds per minute. The latency until the mouse fell from the cylinder (up to $120 \mathrm{~s}$ ) was recorded in three consecutive trials with 2-3 min intervals, and the median latency was used for the following analysis. If the mouse did not fall within $120 \mathrm{~s}$, the latency to fall was recorded as $120 \mathrm{~s}$.

\section{Open-field test}

Each mouse was placed in the center of an open-field apparatus $(50 \mathrm{~cm} \times 50 \mathrm{~cm} \times 40(\mathrm{H}) \mathrm{cm})$ that was illuminated by light-emitting diodes ( $30 \mathrm{~lx}$ at the center of the field) and allowed to move freely for $5 \mathrm{~min}$. The data were collected and analyzed using ImageJ OF4 (O'Hara \& Co., Ltd., Tokyo, Japan), which is modified software that is also based on the public domain ImageJ program. The procedure was performed according to our previous report [30]. 


\section{Acoustic startle response and PPI test}

An acoustic startle reflex measurement system (O'Hara \& Co., Ltd., Tokyo, Japan) was used. The startle response was assessed with various stimulus intensities. Five times of 70 to $120 \mathrm{~dB}(70,75,80,85,90,95,100,110$, and $120 \mathrm{~dB}$ ) white noise stimuli (40 ms) were presented in quasi-random order and random intertrial intervals (1020 s). In the PPI session, mice experienced five trial types: no stimulus; startle stimulus $(120 \mathrm{~dB}, 40 \mathrm{~ms})$ only; prepulse $70 \mathrm{~dB}$ (20 ms, lead time $100 \mathrm{~ms}$ ) and pulse $120 \mathrm{~dB}$; prepulse $75 \mathrm{~dB}(20 \mathrm{~ms}$, lead time $100 \mathrm{~ms})$ and pulse $120 \mathrm{~dB}$; and prepulse $80 \mathrm{~dB}(20 \mathrm{~ms}$, lead time $100 \mathrm{~ms})$ and pulse $120 \mathrm{~dB}$. Each trial was repeated 10 times in quasi-random order and random intertrial intervals (10-20 s). PPI was defined as the percent decline of the startle response: $100-[($ startle amplitude after prepulse and pulse) $/($ startle amplitude after pulse only) $] \times 100$. The procedure was performed according to our previous report [19].

\section{GABA and glutamate contents in the brains}

The frozen tissues were weighed and then homogenized by BioMasher II (Nippi, Inc., Tokyo, Japan) in $500 \mu \mathrm{L}$ of $0.1 \%$ formic acid in acetonitrile (Wako, Tokyo, Japan) containing an internal standard 2-morpholinoethanesulfonic acid (2-MES; Dojindo, Tokyo, Japan). The standard was spiked at a final concentration of $10 \mu \mathrm{M}$. The homogenates were centrifuged at $15,000 \times g$ for $15 \mathrm{~min}$ at $4{ }^{\circ} \mathrm{C}$, and then, the supernatants were collected and filtered through an ISOLUTE PLD + column (Biotage Japan Ltd., Tokyo, Japan). The $40 \mu \mathrm{L}$ filtrates were lyophilized and stored at $-20{ }^{\circ} \mathrm{C}$.

At the time of analysis, the lyophilized samples were dissolved in $1.25 \mathrm{~mL}$ of ultrapure water. The prepared sample solutions $(3 \mu \mathrm{L})$ were then injected on ultraperformance liquid chromatograph coupled to triplequadrupole mass spectrometer (LC/MS) (LCMS-8050; Shimadzu, Kyoto, Japan). The chromatographic conditions were according to the Shimadzu method package using a pentafluorophenylpropyl (PFPP) column. The MS settings, data acquisition and data analysis were in accordance with the manufacturer's instructions for analyzing Primary Metabolites version 2.0 (Cat. \#: 22524865 A, Shimadzu). The relative values of metabolites from the internal standard 2-MES and the weight of corresponding tissues were calculated and used for the following data analysis.

Standard solutions containing GABA (A2129, SigmaAldrich Co. LLC., USA) and L-glutamic acid (G1251, Sigma-Aldrich) at dose ranges of $0.01-3 \mu \mathrm{mol} / \mathrm{L}$ and 0.03-10 $\mu \mathrm{mol} / \mathrm{L}$, respectively, with internal standard 2-MES $(10 \mu \mathrm{M})$ were also applied to the LC/MS system. The concentrations of GABA and glutamate in the sample solutions were determined by the peak heights of the chromatogram. The GABA and glutamate contents per the corresponding tissue weights were calculated.

\section{Statistical analysis}

Statistical analyses were conducted using BellCurve for Excel ver. 3.20 (Social Survey Research Information Co., Ltd., Tokyo, Japan). Significant differences among the multiple groups were analyzed by the Bonferroni multiple comparison test after one-way analysis of variance (ANOVA). Significant differences between two groups were analyzed by Student's $t$-test. The factorial comparisons in some experiments were performed by two-way ANOVA. Data are expressed as the mean with standard error (SE). Statistical significance was defined as a $p$ value less than 0.05 .

\section{Results}

Generation of Gad $1^{\text {STOP-teto }}$ knock-in mice

To confirm the elimination of function of the Gad1 gene by inserting the Neo-STOP-tetO cassette, we first generated homozygous $\mathrm{Gad} 1^{\mathrm{STOP}-\mathrm{tetO} / \mathrm{STOP}-\mathrm{tetO}}$ mice by crossing heterozygous $\mathrm{Gad} 1^{\mathrm{STOP}-\mathrm{tetO} /+}$ parents and assessed whether the Gad1 $1^{\text {STOP-tetO/STOP-tetO }}$ mouse showed the Gad1 knockout phenotypes. Gad1 $1^{\mathrm{STOP}-\mathrm{tetO} / \mathrm{STOP}-\mathrm{tetO}}$ mice, Gad1 $1^{\mathrm{STOP}-\text { tetO/+ }}$ mice and $\mathrm{Gad} 1^{+/+}$mice were born at the expected Mendelian frequency (Fig. 2a). Then, mouse pups were divided into two groups to determine the survival rates and palate formation. All Gad1 $1^{\mathrm{STOP}-}$ tetO/STOP-tetO mice died within 1 day after birth, but Gad$1^{\mathrm{STOP}-\mathrm{tetO} /+}$ mice and Gad1 $1^{+/+}$mice survived (Fig. 2b). All Gad1 $1^{\mathrm{STOP}-\mathrm{tetO} /+}$ and Gad1 $1^{+/+}$mice formed normal palate. However, $57 \%$ of $\mathrm{Gad} 1^{\mathrm{STOP}-\mathrm{tetO} / \mathrm{STOP}-\mathrm{tetO}}$ mice exhibited a cleft palate (Fig. 2c). These phenotypes are the same as those of $\mathrm{Gad1}^{-1-}$ mice previously reported [31]. Western blot analyses demonstrated that the expression of GAD67 protein in the brain was abolished in Gad$1^{\text {STOP-tetO/STOP-tetO }}$ mice with or without cleft palate (Fig. 2d, e). These observations indicate that the insertion of the Neo-STOP-tetO cassette following the Gad1 promoter eliminates the function of the Gad1 gene in mice.

\section{Development of GAD67 knockdown mice}

We then crossed heterozygous male Gad $1^{\mathrm{tTA} /+}$ mice and female Gad1 $1^{\mathrm{STOP}-\mathrm{tetO} /+}$ mice to generate $\mathrm{Gad} 1^{\mathrm{tTA} / \mathrm{STOP}-}$ tetO biallelic knock-in mice. Mice with four genotypes $\left(\mathrm{Gad1}^{+/+}, \mathrm{Gad1} 1^{\mathrm{tA} /+}, \mathrm{Gad1} 1^{\mathrm{STOP}-\mathrm{tetO} /+}, \mathrm{Gad} 1^{\mathrm{tTA} / \mathrm{STOP}-}\right.$ tetO) were born at the expected Mendelian frequency (Fig. 3 legend). Palate formation in mouse neonates with four genotypes was observed, but none of them exhibited the cleft palate (Fig. 3a). Next, the survival rates of these mice were examined in a small population. All Gad1 $1^{+/+}$ mice (total $n=15$ ) survived until 8 weeks of age (Fig. 3b). 


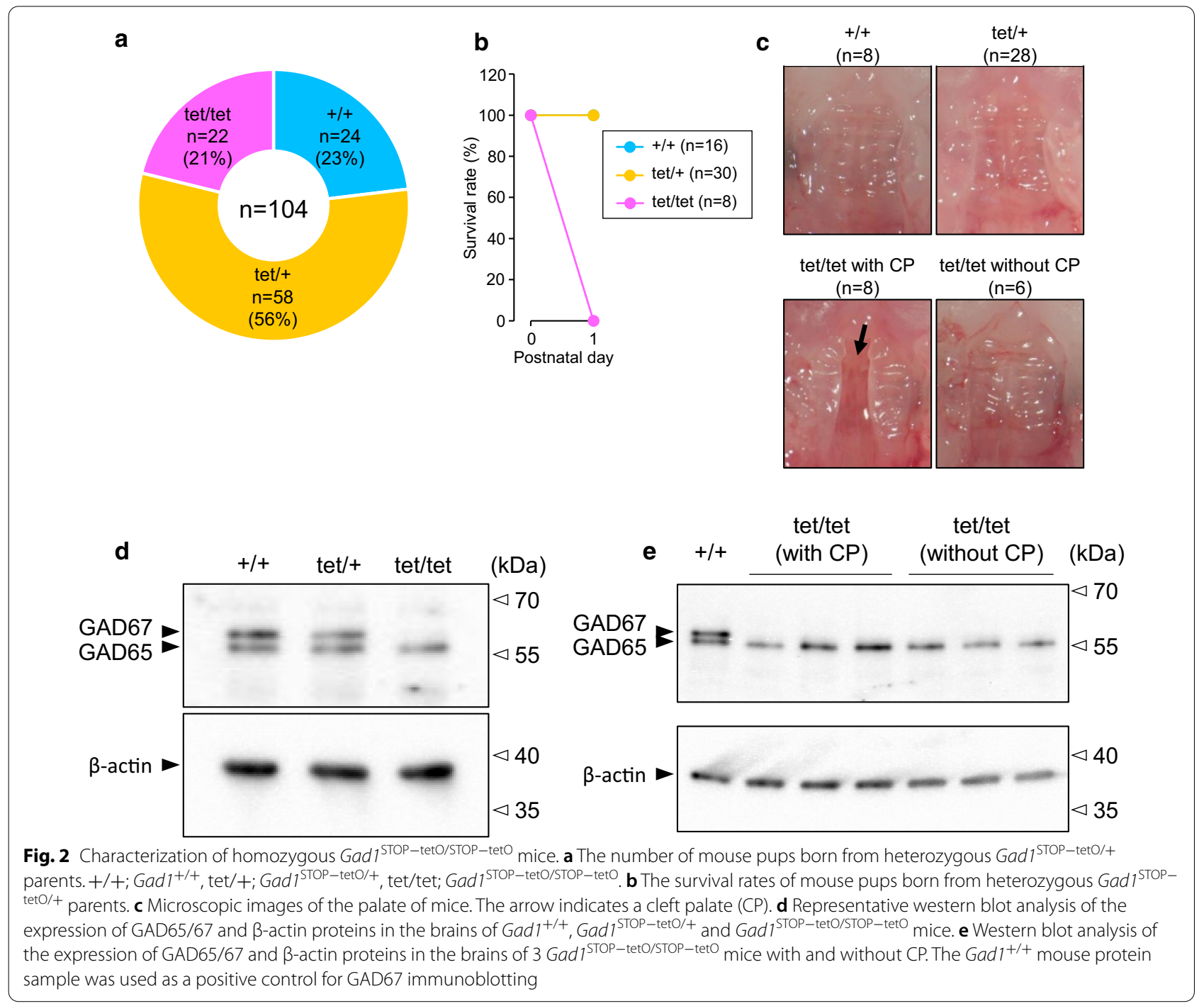

Two Gad1 ${ }^{\mathrm{tTA} /+}$ mice (total $\mathrm{n}=15$ ), one $\mathrm{Gad} 1^{\mathrm{STOP}-\mathrm{tetO} /+}$ mouse (total $\mathrm{n}=17$ ), and eight $\operatorname{Gad}^{\mathrm{tTA} / \mathrm{STOP}-\mathrm{tetO}}$ mice (total $\mathrm{n}=20$ ) died within 8 weeks after birth (Fig. 3b). The proportion of genotypes in our breeding colony (total $\mathrm{n}=1,319)$ at the weaning period (P21-P28) is shown in Fig. 3c. These observations indicate that the survival rate of Gad1 $1^{\mathrm{TA} / \mathrm{STOP}-\mathrm{tetO}}$ mice was lower than that of mice with the other genotypes. The protein levels of GAD67 in the $\operatorname{FCX}(F(3,8)=4.355, p=0.043$, one-way ANOVA $)$ and HIP $(F(3,8)=10.527, p=0.004$, one-way ANOVA) were significantly lower in Gad $1^{\text {tTA/STOP-tetO }}$ mice than $\mathrm{Gad1}^{+/+}$mice at 8 weeks of age (Fig. 3d, e). On the other hand, the protein levels of GAD67 in the CER were not significantly different among the genotypes $(F(3,8)=2.867, p=0.104$, one-way ANOVA) (Fig. 3f).

Next, the expression levels of GAD67 protein in the brains of Gad $1^{\mathrm{tAA} / \mathrm{STOP}-\mathrm{tetO}}$ mice were examined in the absence and presence of Dox treatment. The Dox treatment was performed on the mice at 8-10 weeks of age. We noticed that some Gad1 ${ }^{\text {TA/STOP-tetO }}$ mice died during the 3 weeks after starting the Dox treatment. Approximately $44 \%$ of Gad $1^{\mathrm{tTA} / \mathrm{STOP}-\mathrm{tetO}}$ mice survived just after 3 weeks of Dox treatment (Fig. 4a). The expression levels of GAD67 protein in the FCX $(F(3,8)=20.563, p<0.001$, one-way ANOVA), HIP $(F(3,8)=189.298, p<0.001$, one-way ANOVA) and CER $(F(3,8)=22.760, p<0.001$, one-way ANOVA) were significantly decreased by treatment with Dox in Gad $1^{\text {tTA/STOP-tetO }}$ mice compared with $\mathrm{Gad1}^{+/+}$mice (Fig. 4b-d). Importantly, the expression level of GAD67 protein in the CER of Gad1 ${ }^{\mathrm{tTA} / \mathrm{STOP}-\mathrm{tetO}}$ mice was markedly decreased in the presence of Dox compared with in the absence of Dox (Fig. 4d). By immunofluorescence, GAD67 immunoreactivity in $\mathrm{Gad1}^{+/+}$ mice was detected widely in the brain, particulary at high levels in the olfactory bulb, globus pallidum, olfactory 
a
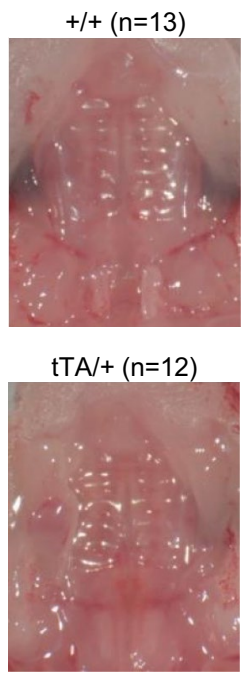

C

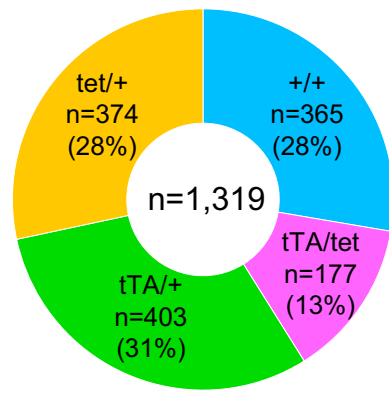

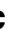

\section{d}

Frontal cortex
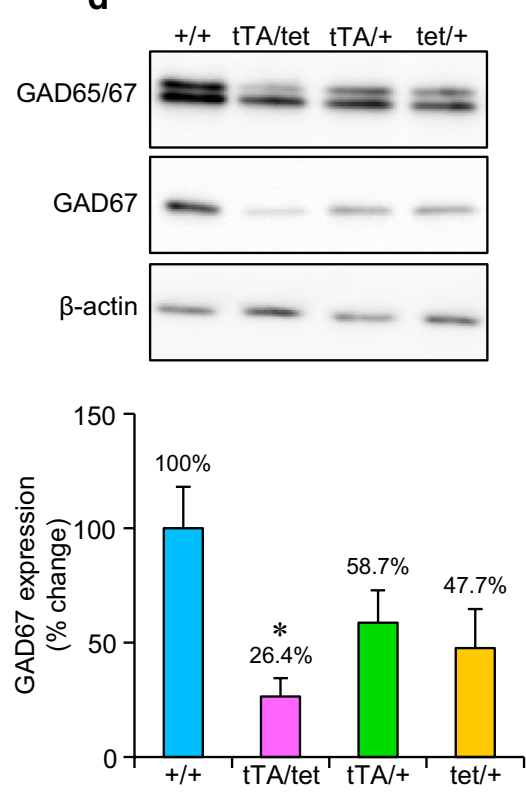

e Hippocampus
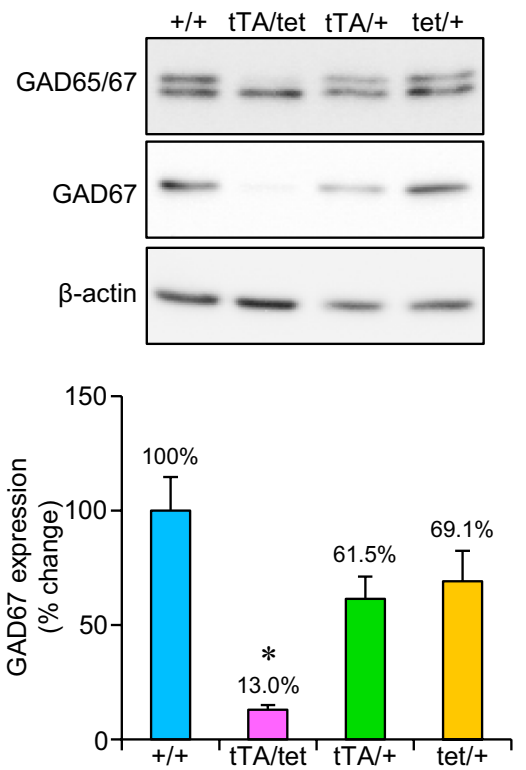

tTA/tet $(n=12)$ b

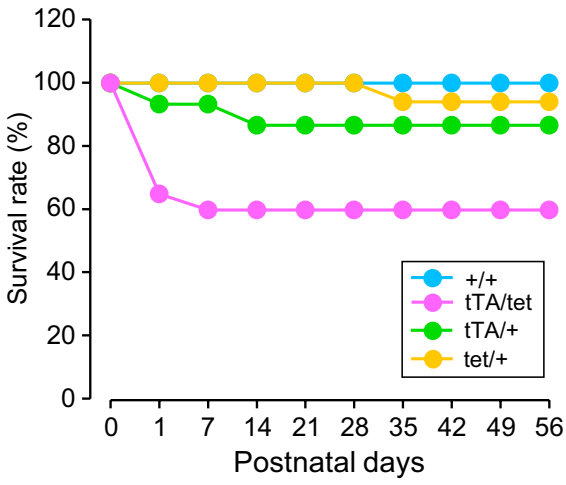

Postnatal days

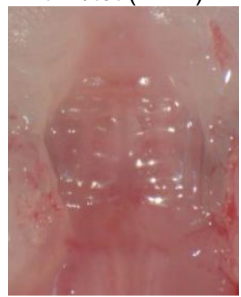

tet $/+(n=15)$

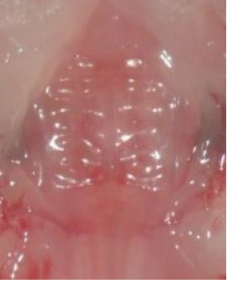

Fig. 3 Characterization of Gad ${ }^{\text {TA/STOP-tetO }}$ mice in the absence of Dox treatment. a Microscopic images of the palates of mice. $\mathbf{b}$ The survival

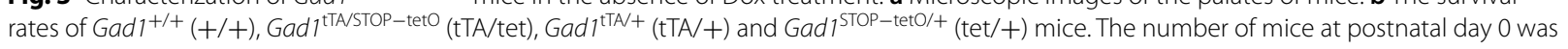
15 (+/+), 20 (tTA/tet), 15 (tTA/+) and 17 (tet/+). c The number of mice with four genotypes at postnatal days 21-28. d-f Representative western blot analysis of the expression of GAD65/67 and $\beta$-actin proteins in the frontal cortex (d), the hippocampus (e) and the cerebellum (f) of Gad 1 +/+, Gad $1^{\text {tASSTOP-tetO }}$ Gad $1^{\text {TAN+ }}$ and Gad $1^{\text {STOP-tetO/+ }}$ mice. $\beta$-Actin was used as a loading control. Three independent mice of the respective genotypes were examined. The band densities of GAD67 and $\beta$-actin were quantified by ImageJ software. GAD67 protein levels were normalized to $\beta$-actin protein expression, and the $\%$ change was calculated relative to $\mathrm{Gad} 1^{+/+}$mice. The means with SE are demonstrated as columns. ${ }^{*} p<0.05$ vs. the value of $\mathrm{Gad}^{+/+}$mice (Bonferroni test)

tubercle, substantia nigra, superior and inferior colliculi, and deep cerebellar nuclei (Fig. 4e, upper panel). In brains of $\mathrm{Gad1}^{\mathrm{tTA} / \mathrm{STOP}-\mathrm{tetO}}$ mice, the overall immunoreactivity was reduced moderately without Dox treatment and severely with the treatment. Dox treatment to $G a d 1^{+/+}$ mice did not affect GAD67 immunoreactivity (data not shown). PV is expressed in a major subclass of GAD67positive inhibitory neurons [32]. No discernible changes 
a

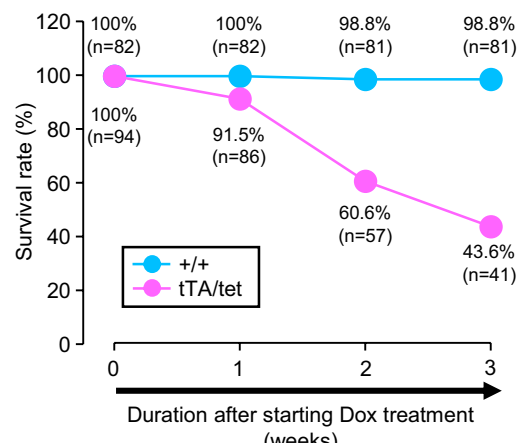

Frontal cortex

b
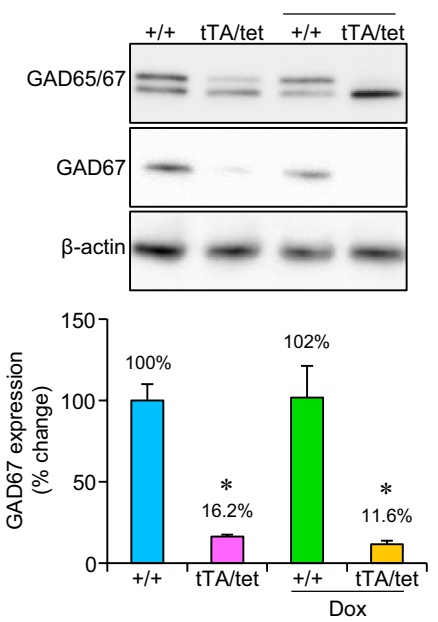

e
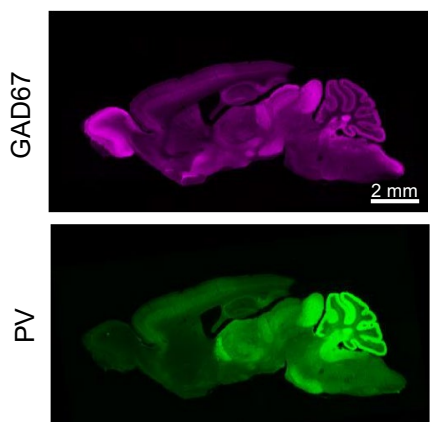

Hippocampus

C
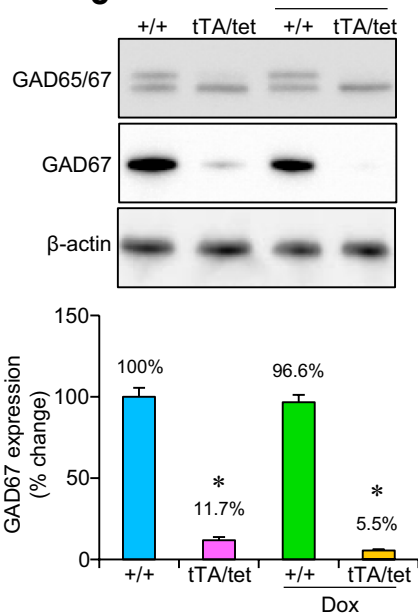

tTA/tet
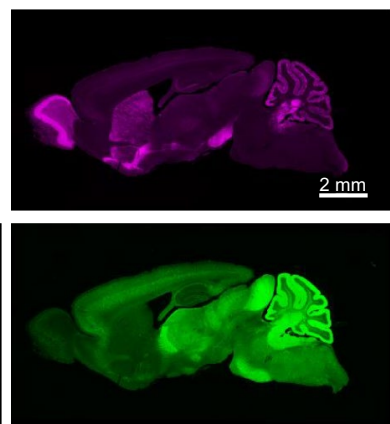

\section{Cerebellum}

d
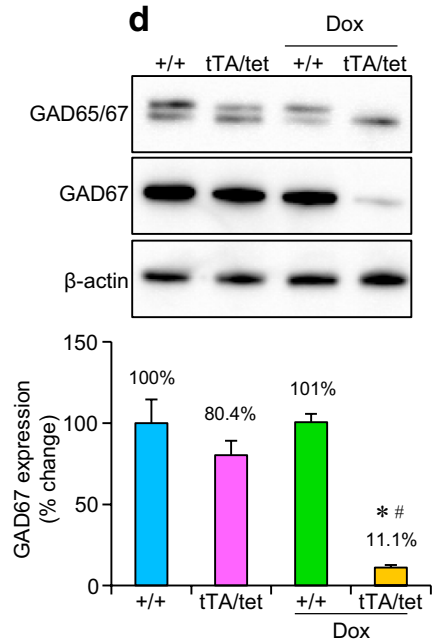

Dox-treated tTA/tet
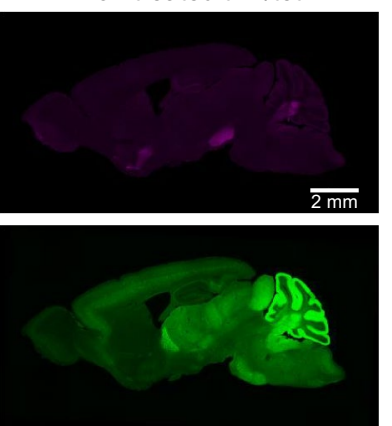

Fig. 4 Characterization of Gad $1^{\text {TA/STOP-tetO }}$ mice in the presence of Dox treatment. a The survival rates of adult Gad $1^{+/+}(+/+)$and Gad $1^{\text {TA/STOP-tetO }}$ (tTA/tet) mice after starting Dox treatment. b-d Representative western blot analysis of the expression of GAD65/67 and $\beta$-actin proteins in the frontal cortex (b), the hippocampus (c) and the cerebellum (d) of Gad1 ${ }^{+/+}$and Gad $1^{\text {TA/STOP-tetO }}$ mice treated and not treated with Dox. $\beta$-Actin was used as a loading control. Three independent mice in the respective groups were examined. The band densities of GAD67 and $\beta$-actin were analyzed by ImageJ software. GAD67 protein levels were normalized to $\beta$-actin protein expression, and the $\%$ change was calculated relative to Gad $1^{+/+}$mice. The means with SE are demonstrated as columns. ${ }^{*} p<0.05$ vs. the value of nontreated Gad $1^{+/+}$mice (Bonferroni test). ${ }^{*} p<0.05$ vs. the value of nontreated Gad $1^{\text {TA/STOP-tetO }}$ mice (Bonferroni test). e Representative immunoreactivities of GAD67 and parvalbumin (PV) proteins in the brain sections of nontreated Gad ${ }^{+/+}$mice, nontreated Gad ${ }^{\text {TA/STOP-tetO }}$ mice and Dox-treated Gad $7^{\text {TA }}$ /STOP-tetO mice. The white bars in the images indicate $2 \mathrm{~mm}$ length 
in PV immunoreactivity were found between $\mathrm{Gad1} 1^{+/+}$ mice and Gad1 $1^{\mathrm{tTA} / \mathrm{STOP}-\mathrm{tetO}}$ mice with or without Dox treatment (Fig. 4e, lower panel). We assessed 3 independent mice in the respective groups and observed similar findings. These results suggest that Dox treatment globally suppresses the expression of GAD67 in the brains of Gad1 ${ }^{\mathrm{TA} / \mathrm{STOP}-\mathrm{tetO}}$ mice.

From these experimental results, GAD67 protein levels were found unexpectedly low in several brain regions in Gad1 ${ }^{\text {TA/STOP-tetO }}$ mice. Therefore, we stopped comparing Dox-treated and Dox-untreated Gad1 $1^{\text {TA/STOP-tetO }}$ mice. Instead, in the following experiments, we compared Dox-treated Gad1 $1^{\mathrm{tTA} / \mathrm{STOP}-\mathrm{tetO}}$ mice and $\mathrm{Gad1}^{+/+}$ mice.

We measured the brain contents of GABA and glutamate in Dox-treated Gad1 $1^{\mathrm{tTA} / \mathrm{STOP}-\mathrm{tetO}}$ mice and Gad1 ${ }^{+/+}$ mice. The GABA content was significantly lower in Doxtreated $\mathrm{Gad} 1^{\mathrm{tTA} / \mathrm{STOP}-\mathrm{tetO}}$ mice than in $\mathrm{Gad1}^{+/+}$mice in the FCX, HIP and CER (Table 1). On the other hand, the glutamate content in the respective brain regions was comparable between these genotypes (Table 1).

\section{Behavioral abnormalities in GAD67 knockdown mice}

We compared the behavioral phenotypes of Gad1 $1^{\mathrm{tA} /}$ STOP-tetO mice with those of $\mathrm{Gad1}^{+/+}$mice in the presence of Dox treatment. To avoid the effects of sex differences, male mice were only used in the following experiments.

We first investigated the body weights and the performance of motor coordination in Dox-treated Gad $1^{\mathrm{tTA} /}$ STOP-tetO and $\mathrm{Gad1}^{+/+}$mice. No difference was observed in the body weights $(t(17)=1.066, p=0.301$, Student's $t$-test, Fig. $5 \mathrm{a}$ ) or the latency to fall from the cylinder in the rotarod test $(t(17)=0.772, p=0.451$, Student's $t$-test, Fig. $5 \mathrm{~b}$ ) between the two genotypes.
We next conducted the open-field test, which is a wellaccepted behavioral test to evaluate the anxiety-like state of rodents [33]. The total distance, total duration of movement, moving speed, distance per movement, and duration per movement were significantly increased in Dox-treated Gad1 $1^{\mathrm{tTA} / \mathrm{STOP}-\mathrm{tetO}}$ mice compared with Dox-treated $\mathrm{Gad1}^{+/+}$mice (Table 2). In contrast, the total number of movement episodes was significantly decreased in Dox-treated Gad $1^{\mathrm{tA} / \mathrm{STOP}-\mathrm{tetO}}$ mice compared with Dox-treated Gad1 ${ }^{+/+}$mice (Table 2). These observations indicate that Gad1 $1^{\mathrm{tTA} / \mathrm{STOP}-\mathrm{tetO}}$ mice walk longer distances with less frequency. In addition, Doxtreated Gad1 ${ }^{\mathrm{tTA} / \mathrm{STOP} \text {-tetO }}$ mice walked a long time in the wall side and a short time in the center region compared with Dox-treated $\mathrm{Gad1}^{+/+}$mice (Table 2 and Fig. 5c), indicating that $G a d 1^{\mathrm{tTA} / \mathrm{STOP}-\mathrm{tetO}}$ mice exhibited anxietylike behavior in the open-field test.

We further assessed acoustic startle responses and PPI responses in Dox-treated Gad ${ }^{\mathrm{tTA} / \mathrm{STOP}-\mathrm{tetO}}$ and $\mathrm{Gad1}^{+/+}$mice. The PPI response provides an operational index of sensorimotor gating, and an impaired PPI response is observed in subjects with schizophrenia [34]. The amplitude of acoustic startle responses was significantly affected by the effect of genotype $\times$ sound level interaction $(F(8,168)=2.745, p=0.007$, two-way ANOVA). The simple main effect of genotypes was statistically significant at the sound levels of $110 \mathrm{~dB}(F(1$, $92)=6.345, p=0.014)$ and $120 \mathrm{~dB}(F(1,92)=13.550$, $p<0.001$ ) (Fig. 5d). The PPI responses were significantly affected by the effect of prepulse intensity $(F(2,42)=6.713, p=0.003$, two-way ANOVA) but not by the effect of genotype $\times$ prepulse intensity interaction $(F(2,42)=0.577, p=0.566$, two-way ANOVA) or genotype $(F(1,21)=0.514, p=0.481$, two-way ANOVA $)$ (Fig. 5e).

Table 1 Brain GABA and glutamate contents

\begin{tabular}{|c|c|c|c|c|c|}
\hline & \multicolumn{2}{|c|}{ Contents (nmol/mg tissue) } & \multirow[t]{2}{*}{ \% Reduction } & \multirow[t]{2}{*}{$t$ values } & \multirow[t]{2}{*}{$p$ value } \\
\hline & Gad1+/+ & Gad $1^{\text {tTA/STOP-tetO }}$ & & & \\
\hline \multicolumn{6}{|l|}{$G A B A$} \\
\hline Frontal cortex & $0.632 \pm 0.027$ & $0.462 \pm 0.019$ & 27.0 & 5.052 & $<0.001$ \\
\hline Hippocampus & $0.850 \pm 0.033$ & $0.546 \pm 0.019$ & 35.8 & 7.844 & $<0.001$ \\
\hline Cerebellum & $0.651 \pm 0.026$ & $0.281 \pm 0.011$ & 56.8 & 12.753 & $<0.001$ \\
\hline \multicolumn{6}{|l|}{ Glutamate } \\
\hline Frontal cortex & $5.550 \pm 0.112$ & $5.617 \pm 0.156$ & -1.2 & 0.350 & 0.731 \\
\hline Hippocampus & $5.477 \pm 0.148$ & $5.479 \pm 0.171$ & 0.0 & 0.008 & 0.994 \\
\hline Cerebellum & $4.184 \pm 0.086$ & $4.356 \pm 0.127$ & -4.1 & 1.144 & 0.268 \\
\hline
\end{tabular}

Dox-treated Gad1 $^{+/+}(\mathrm{n}=10)$ and Gad $1^{\text {tTA/STOP-tetO }}(\mathrm{n}=9)$ mice were used to determine the brain contents of GABA and glutamate. Data represent the mean \pm SE. $\%$ Reduction was calculated by $100-\left[\right.$ (the mean value of Gad $1^{\text {tTA } / S T O P-t e t O}$ mice)/(the mean value of Gad $1^{+/+}$mice) $] \times 100$. A $p$ value less than 0.05 was considered a significant difference (Student's $t$-test) 


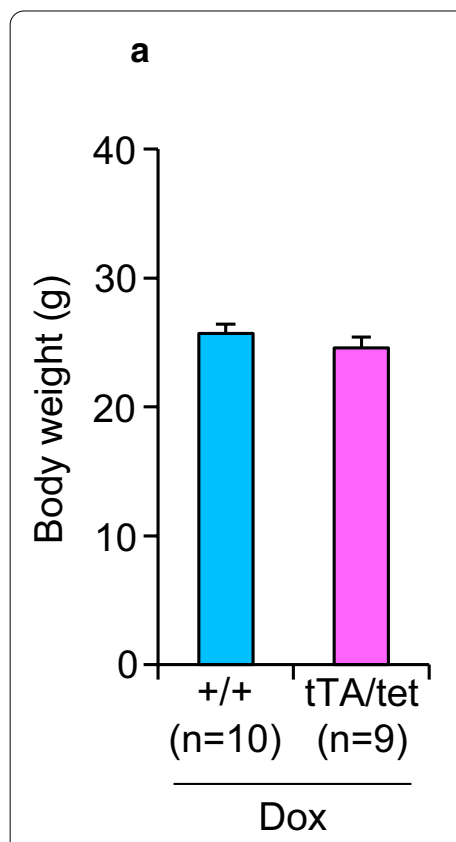

b

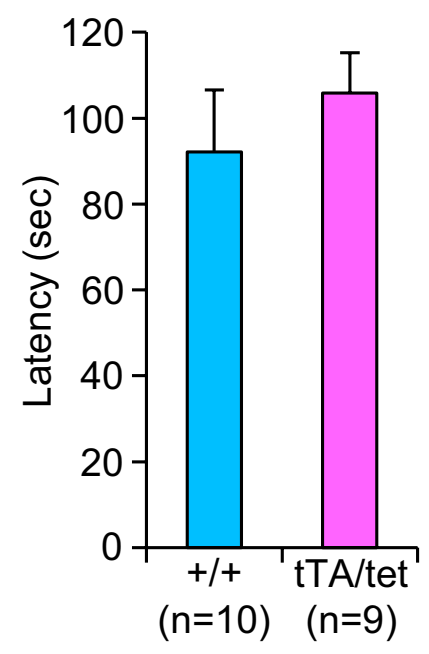

c

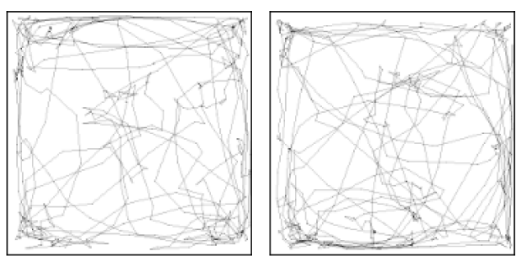

Dox-treated Gad1+/+

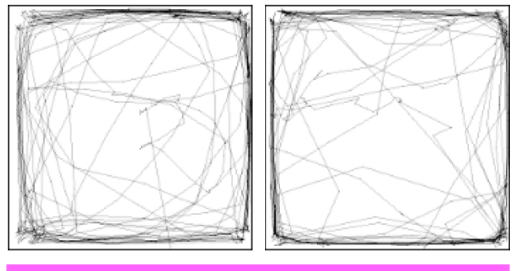

Dox-treated Gad1 1TA/STOP-tetO

\section{Dox}
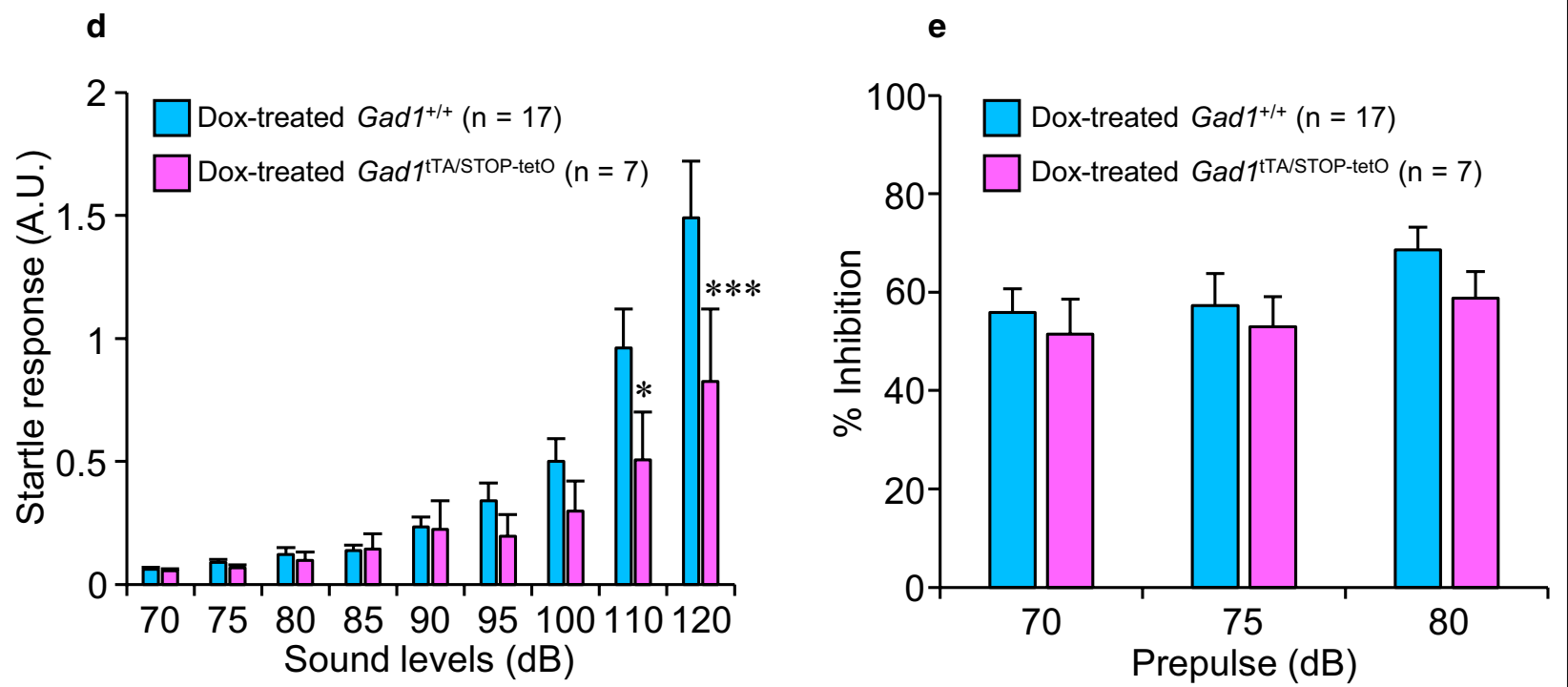

Fig. 5 Behavioral consequences of GAD67 knockdown in mice. a, b Body weights and latency to fall from a cylinder in the rotarod test for Dox-treated Gad1 ${ }^{+/+}$and Gad $1^{\text {tA/STOP-tetO }}$ mice. $\mathbf{c}$ Examples of the path traveled in the open-field test by two Gad1 ${ }^{+/+}$and two Gad $1^{\text {tTA/STOP-tetO }}$ mice treated with Dox. $\mathbf{d}$ Acoustic startle responses of Dox-treated Gad $1^{+/+}$and Gad $1^{\text {tTA/STOP-tetO }}$ mice. Startle amplitudes by the sounds indicate the startle responses (A.U.). ${ }^{*} p<0.05$ and ${ }^{* * *} p<0.001$ between genotypes (simple main effect of two-way ANOVA). e PPI responses of Dox-treated Gad1 $^{+/+}$and Gad $1^{\text {TA/STOP-tetO }}$ mice. PPI was defined as the percent decline in the startle response (\% Inhibition)

\section{Discussion}

We first generated $\operatorname{Gad} 1^{\mathrm{STOP}-t e t O}$ knock-in mice. All homozygous Gad1 ${ }^{\mathrm{STOP}-\mathrm{tetO} / \mathrm{STOP} \text {-tetO }}$ mice died on the day of birth, and $57 \%$ of $\mathrm{Gad}_{1}{ }^{\mathrm{STOP}-\mathrm{tetO} / \mathrm{STOP}-\mathrm{tetO}}$ mice exhibited a cleft palate. The expression of GAD67 protein was lacking in the brains of $\mathrm{Gad}_{1}{ }^{\mathrm{STOP}}$-tetO/STOP-tetO mice with or without the cleft palate. These phenotypes in Gad1 ${ }^{\text {STOP-tetO/STOP-tetO }}$ mice are consistent with those in $\mathrm{Gad1}^{-1-}$ mice $[15,31]$. Therefore, the function of the Gad1 gene was eliminated by the insertion of the NeoSTOP-tetO cassette in the $5^{\prime}$-untranslated region of the Gad1 gene in mice. It has been reported that neonatal death in $\mathrm{Gad1}^{-1-}$ mice is caused by respiratory failure rather than impairment of suckling $[15,35]$. Therefore, 
Table 2 Summary of exploratory behaviors in the open-field test

\begin{tabular}{|c|c|c|c|c|}
\hline & Gad1 $^{+/+}$ & Gad1 $1^{\text {tTA/STOP-tetO }}$ & $t$ values & $p$ values \\
\hline Total distance (cm) & $2434.4 \pm 102.7$ & $3495.0 \pm 179.7$ & 5.389 & $<0.001$ \\
\hline Total duration of movement (s) & $166.8 \pm 4.9$ & $185.7 \pm 5.5$ & 2.235 & 0.036 \\
\hline Total number of movement episode & $95.4 \pm 2.1$ & $86.7 \pm 2.6$ & 2.330 & 0.029 \\
\hline Moving speed $(\mathrm{cm} / \mathrm{s})$ & $13.1 \pm 0.3$ & $17.8 \pm 0.7$ & 6.784 & $<0.001$ \\
\hline Distance per movement (cm) & $23.4 \pm 1.3$ & $38.7 \pm 3.1$ & 5.380 & $<0.001$ \\
\hline Duration per movement (s) & $1.8 \pm 0.1$ & $2.2 \pm 0.1$ & 3.295 & 0.003 \\
\hline Time spent in the wall side (s) & $246.9 \pm 5.5$ & $271.6 \pm 5.3$ & 2.671 & 0.014 \\
\hline Time spent in the center region (s) & $53.1 \pm 5.5$ & $28.4 \pm 5.3$ & 2.671 & 0.014 \\
\hline \% Time spent in the center region & $17.7 \pm 1.8$ & $9.5 \pm 1.8$ & 2.670 & 0.014 \\
\hline
\end{tabular}

Exploratory behaviors were measured for $5 \mathrm{~min}$ in the open-field in Dox-treated Gad $1^{+/+}(\mathrm{n}=17)$ and Gad ${ }^{\text {tTA/STOP-tetO }}(\mathrm{n}=7)$ mice. Data represent the mean $\pm \mathrm{SE}$. A $p$ value less than 0.05 was considered a significant difference (Student's $t$-test)

neonatal death in Gad1 $1^{\text {STOP-tetO/STOP-tetO }}$ mice may also be caused by respiratory failure.

We next developed Gad1 $1^{\mathrm{tTA} / \mathrm{STOP}-\mathrm{tetO}}$ biallelic knockin mice by crossing Gad $1^{\mathrm{tTA} /+}$ and Gad $1^{\mathrm{STOP}-\mathrm{tetO} /+}$ parents. Approximately $40 \%$ of Gad1 $1^{\mathrm{tTA} / \mathrm{STOP}-\mathrm{tetO}}$ mice died on the day of birth, and the number of Gad1 $1^{\mathrm{tTA} / \mathrm{STOP}-\mathrm{tetO}}$ mice at P21-P28 in our breeding colony was smaller than the numbers of mice with the other genotypes. None of the Gad $1^{\mathrm{tTA} / \mathrm{STOP}-\mathrm{tetO}}$ mice demonstrated a cleft palate. Unexpectedly, some adult Gad1 $1^{\mathrm{tTA} / \mathrm{STOP}-\text { tetO }}$ mice died by treatment with Dox. Therefore, GAD67 is important for survival not only in the neonatal period but also in adulthood. However, the cause of death in Dox-treated Gad1 ${ }^{\text {tTA/STOP-tetO }}$ mice is currently unknown. To resolve this question, pathological examination is required in a future study.

Adult mice with Gad1 haplodeficiency demonstrated an approximately 40\% reduction in GAD67 protein levels in the whole brain compared with $\mathrm{Gad1} 1^{+/+}$mice [27]. Consistently, we observed that heterozygous Gad1 $1^{\mathrm{tA} /+}$ and heterozygous $\mathrm{Gad} 1^{\mathrm{STOP}-\mathrm{tetO} /+}$ knock-in mice exhibited a $30-50 \%$ reduction in GAD67 protein levels in the FCX, HIP and CER compared with $G a d 1^{+/+}$mice. In the absence of Dox treatment, the expression level of GAD67 protein in $\mathrm{Gad} 1^{\mathrm{tTA} / \mathrm{STOP}-\mathrm{tetO}}$ mice relative to $\mathrm{Gad} 1^{+/+}$ mice was dependent on the brain regions. In the immunoblotting analysis, the expression of GAD67 protein in the CER was comparable between $\mathrm{Gad} 1^{\mathrm{tTA} / \mathrm{STOP}-\mathrm{tetO}}$ mice and $\mathrm{Gad1}^{+/+}$mice. However, the expression of GAD67 protein in the FCX and HIP was significantly lower in Gad1 ${ }^{\text {tTA/STOP-tetO }}$ mice than Gad1 $1^{+/+}$mice. Importantly, in the presence of Dox treatment, GAD67 expression was reduced by approximately $90 \%$ in the brains of Gad $1^{\mathrm{tTA} /}$ STOP-tetO mice, compared with Dox-treated Gad1 $1^{+/+}$ mice. The brain-wide reduction of GAD67 expression in Dox-treated Gad1 $1^{\text {tTA/STOP-tetO }}$ mice was also observed in the immunofluorescence analysis. These findings suggest that GAD67 expression is suppressed by treatment with Dox in the brains of Gad1 $1^{\mathrm{tTA} / \mathrm{STOP}-\mathrm{tetO}}$ mice.

In adult mice with Gad1 haplodeficiency, the GABA content in the brain was reduced by $7-20 \%$ from those in wild-type control mice $[15,32]$. In this study, we found that the GABA contents in the FCX, HIP and CER of Dox-treated $G a d 1^{\mathrm{tTA} / \mathrm{STOP}-\mathrm{tetO}}$ mice were reduced by 27.0-56.8\% from those in Dox-treated Gad1 ${ }^{+/+}$mice. This result is inferred that the amount corresponding to the reduced GABA content compared to the GABA content in the brain of $\mathrm{Gad1}^{+/+}$mice is derived from the amount biosynthesized by GAD67 expression in the brain of Gad1 $1^{\mathrm{tTA} / \mathrm{STOP}-\mathrm{tetO}}$ mice. Therefore, the GABA reduction in the brains of Dox-treated Gad1 ${ }^{\text {tTA/STOP-tetO }}$ mice was larger than that in Gad1 haplodeficient mice. Because approximately half of the brain GABA is produced by GAD65 in adulthood [36], the remaining GABA in the brain of Dox-treated Gad1 $1^{\mathrm{tTA} / \mathrm{STOP}-\mathrm{tetO}}$ mice is mainly synthesized by GAD65. The brain glutamate contents in Dox-treated Gad1 $1^{\mathrm{tTA} / \mathrm{STOP}-\mathrm{tetO}}$ mice were comparable to those in Dox-treated $\mathrm{Gad} 1^{+/+}$mice. Therefore, the glutamatergic system may be normal in Dox-treated Gad1 ${ }^{\mathrm{tTA} / \mathrm{STOP}-\mathrm{tetO}}$ mice.

GAD67 haplodeficient mice demonstrated several abnormal behaviors, such as hyper-locomotor activity, reduced interactions with an unfamiliar mouse, and aggressive behavior. However, the emotional behaviors in Gad1 haplodeficient mice were normal in the open-field test, the light-dark avoidance test and the elevated plusmaze test $[21,23]$. In the current open-field test, Doxtreated Gad1 $1^{\mathrm{tTA} / \mathrm{STOP}-\mathrm{tetO}}$ mice walked longer distances than Dox-treated $G a d 1^{+/+}$mice. In addition, Dox-treated Gad1 ${ }^{\mathrm{tTA} / \mathrm{STOP}-\mathrm{tetO}}$ mice preferentially walked for more time along the walls and for less time in the center region. These observations indicate that Dox-treated Gad1 $1^{\mathrm{tTA} /}$ STOP-tetO mice exhibited behavioral abnormalities, including the hyper-locomotor activity and anxiety-like 
behavior, in the open-field test. Since Gad1 ${ }^{\mathrm{tTA} / \mathrm{STOP}-\mathrm{tetO}}$ mice exhibited normal body weight and motor coordination in the presence of Dox treatment, the changes in exploratory behavior are unlikely to be associated with physical dysfunction. It is well accepted that inhibition of GABAergic tone elicits anxiety-like behavior in the open-field test [33]. Therefore, the reduction in brain GABA in Dox-treated Gad $1^{\mathrm{tTA} / \mathrm{STOP}-\mathrm{tetO}}$ mice may cause the induction of anxiety-like behavior. The mice lacking GAD67 in protein phosphatase 1 regulatory subunit 2 (Ppp1r2)-expressing cells, in which Cre recombinase expression is largely confined to GABA interneurons of the cerebral cortex and the hippocampus, demonstrated the hyper-locomotor activity and anxiety-like behavior in the open-field test [37]. In addition, we recently reported that mice lacking GAD67 in somatostatin-expressing GABA interneurons demonstrated anxiety-like behavior in the open-field test without affecting locomotor activity [20]. Therefore, the anxiety-like behavior in Dox-treated Gad1 ${ }^{\text {tTA/STOP-tetO }}$ mice may be due to GAD67 knockdown from somatostatin-expressing GABA interneurons in cortical and hippocampal areas. In addition, the hyperlocomotor activity in Dox-treated Gad1 ${ }^{\text {tTA/STOP-tetO mice }}$ may be associated with GAD67 knockdown from the other subtypes of GABA interneurons.

In this study, Dox-treated Gad $1^{\mathrm{tTA} / \mathrm{STOP}-\mathrm{tetO}}$ mice showed a normal response to PPI. Therefore, global knockdown of GAD67 does not affect the PPI response. However, we previously reported that mice with conditional Gad1 heterozygous knockout predominantly in parvalbumin-positive cells demonstrated an impaired response to PPI [19]. It is possible that a mild reduction in GAD67 in parvalbumin-positive cells might be required for impairing the PPI response. Interestingly, the startle responses elicited by large acoustic stimuli were impaired in Dox-treated Gad1 ${ }^{\text {tTA/STOP-tetO }}$ mice. The acoustic startle response is a simple reflex of animals that results in a whole body motor response elicited by hearing a loud sound. Multiple neural circuits from the cochlear nucleus to motoneurons contributes to elicit the acoustic starthe reflex [38]. Therefore, it is possible that Dox-treated Gad1 $1^{\text {tAA/STOP-tetO }}$ mice might exhibit the impairment of the acoustic startle reflex associated with those neural circuits. In addition, GABAergic interneurons expressing GAD67 proteins constitute auditory neural networks and contribute to auditory function [39-41]. Therefore, global knockdown of GAD67 in the brain might induce the impairment of auditory function. To note that the behavioral responses by intensity of pre-pulse in the control mice were different between the present study and the previous study [19]. There are several possible reasons to explain the different observations. First, it may be related to the difference in the environment during development between these two types of mice because all mice in the present study were born from GAD67 haplodeficient $\left(\mathrm{Gad1} 1^{\mathrm{STOP}-\mathrm{tetO} /+}\right)$ mothers and cared by the same mothers. We previously reported that wildtype $\left(\mathrm{Gad1}^{+/+}\right)$mice born from GAD67 haplodeficient $\left(\right.$ Gad $\left.1^{\mathrm{GFP} /+}\right)$ mothers exhibited the vulnerability to stress at the adult age [42]. In addition, it has been reported that the anxious state in mother mice affects behavioral phenotypes in their pups at the adult age [43]. Second, we used wild-type $\left(\mathrm{Gad1}^{+/+}\right)$mice as the control, but Fujihara et al. [19] used Gad1 $1^{\text {flox/+ }}$ mice as the control. The difference in genotypes might affect the reaction of PPI in mice. Third, there is difference whether the mice were subjected to Dox treatment or not. It can not be excluded the possibility that the Dox treatment affected the PPI reaction in mice. Further experiments are necessary to resolve the difference in the baseline reaction of prepulse between the studies.

The GAD1 gene and GAD67 protein have often been targeted in human studies to elucidate an association with the pathophysiology of psychiatric disorders [4446]. Reduced full-length GAD1 transcript and GAD67 protein is a consistent finding in the postmortem brains of patients with several psychiatric disorders including schizophrenia, bipolar disorder and major depressive disorder [7-12]. Because GAD67 reduction was predominantly observed in parvalbumin-positive GABAergic interneurons in the postmortem brains of schizophrenic patients [47-49], mice with conditional knockout of GAD67 in parvalbumin-positive cells have been used as an animal model of schizophrenia [18, 19, 50,51]. On the other hand, the specific subsets of GABAergic interneurons reducing GAD67 expression have not yet been identified in other psychiatric disorders, which might indicate that GAD67 expression is globally reduced in the brain of subjects with the other psychiatric disorders. In this study, global knockdown of GAD67 elicited anxiety-like behavior in mice. Therefore, we suggest the possibility that the global reduction in GAD1 transcript and GAD67 protein in the brain might be related to the occurrence of anxiety symptoms frequently comorbid in several psychiatric disorders.

We did not examine whether administration of anxiolytic, antidepressant or antipsychotic drugs improves anxiety-like behavior in Dox-treated Gad1 ${ }^{\text {tTA/STOP-tetO }}$ mice. Because of the high lethality rate, we could not immediately prepare a sufficient number of animals for conducting a pharmacological study. Therefore, we will determine the utility of Dox-treated Gad1 $1^{\mathrm{tA} / \mathrm{STOP}-\text { tetO }}$ mice as a tool for screening potential medications for anxiety symptoms in a future study.

In summary, Gad1 ${ }^{\text {tTA/STOP-tetO }}$ biallelic knock-in mice showed GAD67-knockdown phenotypes when treated 
with Dox. We suggest that the global reduction in GAD67 elicits emotional and auditory abnormalities in mice. The use of GAD67 knockdown mice will provide new insights into the neurobiological impact of GAD67 dysfunction and elucidate the neurobiological mechanisms of emotional abnormalities associated with psychiatric disorders.

\begin{abstract}
Abbreviations
GAD67: Glutamate decarboxylase 67; GAD65: Glutamate decarboxylase 65; Dox: Doxycycline; GABA: $y$-Aminobutyric acid; tTA: Tetracycline-controlled transcriptional activator; tetO: Tetracycline operator site; FCX: Frontal cortex; HIP: Hippocampus; CER: Cerebellum; CP: Cleft palate; PV: Parvalbumin; PPI: Prepulse inhibition; ANOVA: Analysis of variance; SE: Standard error.
\end{abstract}

\section{Acknowledgements}

We are grateful to Dr. Kunihiko Obata for his encouragement. We would like to thank Yukari Shiba for her help with animal care and experiments. We also thank the staff at the Bioresource Center of Gunma University Graduate School of Medicine for technical support.

\section{Authors' contributions}

SM and YY conceptualization; SM data curation; SM formal analysis; YY and KS funding acquisition; SM, $\mathrm{HO}$ and TH investigation; $S M, T K, K F$ and $Y Y$ methodology; SM project administration; JN, MT, SI, MW, KT, MA and KS resources; YY supervision; SM and YY writing-original draft; all authors writing-review and editing.

\section{Funding}

This work was supported by the Japan Society for the Promotion of Science (JSPS) KAKENHI Grant Numbers 26290002 (YY), 15 H05872 (YY), $17 \mathrm{H} 05550$ (YY), $19 \mathrm{~K} 06881$ (YY) and 16H06276 (AdAMS) (KS). This work was the result of using research equipment shared in MEXT Project for promoting public utilization of advanced research infrastructure (Program for supporting introduction of the new sharing system) Grant Number JPMXS0420600120. This project was partly supported by the Takeda Science Foundation (YY).

\section{Availability of data and materials}

All data are available within the manuscript.

\section{Ethics approval and consent to participate}

This study was performed in accordance with the Guidelines for Animal Experimentation at Gunma University Graduate School of Medicine and was approved by the Gunma University Ethics Committee (Permit Number: 14-006 and 19-009). Every effort was made to minimize the number of animals used and their suffering.

\section{Consent for publication}

Not applicable.

\section{Competing interests}

The authors declare that they have no conflicts of interest with the contents of this manuscript.

\footnotetext{
Author details

1 Department of Genetic and Behavioral Neuroscience, Gunma University Graduate School of Medicine, Maebashi 371-8511, Japan. ${ }^{2}$ Laboratory for Analytical Instruments, Education and Research Support Center, Gunma University Graduate School of Medicine, Maebashi 371-8511, Japan. ${ }^{3}$ Division of Oral Physiology, Department of Oral Function and Morphology, Tohoku University Graduate School of Dentistry, Sendai 980-8575, Japan. ${ }^{4}$ Laboratory for Behavioral Genetics, RIKEN Brain Science Institute, Wako 351-0198, Japan. ${ }^{5}$ Department of Anatomy, Faculty of Medicine, Hokkaido University, Sapporo 060-8638, Japan. ${ }^{6}$ Department of Neuropsychiatry, Keio University School of Medicine, Tokyo 160-8582, Japan. ${ }^{7}$ Department of Animal Model Development, Brain Research Institute, Niigata University, Niigata 951-8585, Japan.
}

Received: 15 September 2020 Accepted: 7 December 2020

Published online: 07 January 2021

\section{References}

1. Ji F, Kanbara N, Obata K. GABA and histogenesis in fetal and neonatal mouse brain lacking both the isoforms of glutamic acid decarboxylase. Neurosci Res. 1999;33:187-94.

2. Soghomonian JJ, Martin DL. Two isoforms of glutamate decarboxylase: why? Trends Pharmacol Sci. 1998;19:500-5.

3. Esclapez M, Tillakaratne NJ, Kaufman DL, Tobin AJ, Houser CR. Comparative localization of two forms of glutamic acid decarboxylase and their mRNAs in rat brain supports the concept of functional differences between the forms. J Neurosci. 1994;14:1834-55.

4. Obata K, Fukuda T, Konishi S, Ji F-Y, Mitoma H, Kosaka T. Synaptic localization of the $67,000 \mathrm{~mol}$. wt isoform of glutamate decarboxylase and transmitter function of GABA in the mouse cerebellum lacking the 65,000 mol. wt isoform. Neuroscience. 1999;93:1475-82.

5. Martin DL, Martin SB, Wu SJ, Espina N. Regulatory properties of brain glutamate decarboxylase (GAD): the apoenzyme of GAD is present principally as the smaller of two molecular forms of GAD in brain. J Neurosci. 1991a;11:2725-31.

6. Martin DL, Martin SB, Wu SJ, Espina N. Cofactor interactions and the regulation of glutamate decarboxylase activity. Neurochem Res. 1991b;16:243-9.

7. Guidotti A, Auta J, Davis JM, Gerevini VD, Dwivedi Y, Grayson DR, et al. Decrease in reelin and glutamic acid decarboxylase67 (GAD67) expression in schizophrenia and bipolar disorder. Arch Gen Psychiatry. 2000;57:1061-9.

8. Hashimoto T, Arion D, Unger T, Maldonado-Avilés JG, Morris HM, Volk DW, et al. Alterations in GABA-related transcriptome in the dorsolateral prefrontal cortex of subjects with schizophrenia. Mol Psychiatry. 2008;13:147-61.

9. Volk DW, Austin MC, Pierri JN, Sampson AR, Lewis DA. Decreased glutamic acid decarboxylase67 Messenger RNA expression in a subset of prefrontal cortical $\gamma$-aminobutyric acid neurons in subjects with schizophrenia. Arch Gen Psychiatry. 2000;57:237.

10. Karolewicz B, Maciag D, O'Dwyer G, Stockmeier CA, Feyissa AM, Rajkowska G. Reduced level of glutamic acid decarboxylase-67 kDa in the prefrontal cortex in major depression. Int J Neuropsychopharmacol. 2010;13:411-20.

11. Scifo E, Pabba M, Kapadia F, Ma T, Lewis DA, Tseng GC, et al. Sustained molecular pathology across episodes and remission in major depressive disorder. Biol Psychiatry. 2018;83:81-9.

12. Tao R, Davis KN, Li C, Shin JH, Gao Y, Jaffe AE, et al. GAD1 alternative transcripts and DNA methylation in human prefrontal cortex and hippocampus in brain development, schizophrenia. Mol Psychiatry. 2018;23:1496-505.

13. Giacopuzzi E, Gennarelli M, Minelli A, Gardella R, Valsecchi P, Traversa $M$, et al. Exome sequencing in schizophrenic patients with high levels of homozygosity identifies novel and extremely rare mutations in the GABA/glutamatergic pathways. PLoS ONE. 2017;12:e0182778.

14. Magri C, Giacopuzzi E, La Via L, Bonini D, Ravasio V, Elhussiny MEA, et al. A novel homozygous mutation in GAD1 gene described in a schizophrenic patient impairs activity and dimerization of GAD67 enzyme. Sci Rep. 2018:8:15470

15. Asada H, Kawamura Y, Maruyama K, Kume H, Ding RG, Kanbara N, et al. Cleft palate and decreased brain gamma-aminobutyric acid in mice lacking the 67-kDa isoform of glutamic acid decarboxylase. Proc Natl Acad Sci USA. 1997:94:6496-9.

16. Obata K, Hirono M, Kume N, Kawaguchi Y, Itohara S, Yanagawa Y. GABA and synaptic inhibition of mouse cerebellum lacking glutamate decarboxylase 67. Biochem Biophys Res Commun. 2008;370:429-33.

17. Heusner CL, Beutler LR, Houser CR, Palmiter RD. Deletion of GAD67 in dopamine receptor-1 expressing cells causes specific motor deficits. Genesis. 2008;46:357-67.

18. Kuki T, Fujihara K, Miwa H, Tamamaki N, Yanagawa Y, Mushiake H. Contribution of parvalbumin and somatostatin-expressing GABAergic neurons to slow oscillations and the balance in beta-gamma oscillations across cortical layers. Front Neural Circuits. 2015;9:6. 
19. Fujihara K, Miwa H, Kakizaki T, Kaneko R, Mikuni M, Tanahira C, et al. Glutamate decarboxylase 67 deficiency in a subset of GABAergic neurons induces schizophrenia-related phenotypes. Neuropsychopharmacology. 2015;40:2475-86.

20. Miyata S, Kumagaya R, Kakizaki T, Fujihara K, Wakamatsu K, Yanagawa Y. Loss of glutamate decarboxylase 67 in somatostatin-expressing neurons leads to anxiety-like behavior and alteration in the Akt/GSK3 $\beta$ signaling pathway. Front Behav Neurosci. 2019;13:131.

21. Sandhu KV, Lang D, Müller B, Nullmeier S, Yanagawa Y, Schwegler H, et al. Glutamic acid decarboxylase 67 haplodeficiency impairs social behavior in mice. Genes Brain Behav. 2014;13:439-50.

22. Chen L, McKenna JT, Leonard MZ, Yanagawa Y, McCarley RW, Brown RE. GAD67-GFP knock-in mice have normal sleep-wake patterns and sleep homeostasis. NeuroReport. 2010;21:216-20.

23. Smith KM. Hyperactivity in mice lacking one allele of the glutamic acid decarboxylase 67 gene. Atten Defic Hyperact Disord. 2018;10:267-71.

24. Nullmeier S, Elmers C, D'Hanis W, Sandhu KVK, Stork O, Yanagawa Y, et al. Glutamic acid decarboxylase 67 haplodeficiency in mice: consequences of postweaning social isolation on behavior and changes in brain neurochemical systems. Brain Struct Funct. 2020;225:1719-42.

25. Das AT, Tenenbaum L, Berkhout B. Tet-on systems for doxycycline-inducible gene expression. Curr Gene Ther. 2016;16:156-67.

26. Tanaka KF, Matsui K, Sasaki T, Sano H, Sugio S, Fan K, et al. Expanding the repertoire of optogenetically targeted cells with an enhanced gene expression system. Cell Rep. 2012;2:397-406.

27. Wang Y, Kakizaki T, Sakagami H, Saito K, Ebihara S, Kato M, et al. Fluorescent labeling of both GABAergic and glycinergic neurons in vesicular GABA transporter (VGAT)-Venus transgenic mouse. Neuroscience. 2009;164:1031-43.

28. Tanaka KF, Ahmari SE, Leonardo ED, Richardson-Jones JW, Budreck EC, Scheiffele $P$, et al. Flexible accelerated STOP tetracycline operator-knockin (FAST): a versatile and efficient new gene modulating system. Biol Psychiatry. 2010;67:770-3.

29. Hanamura K, Mizui T, Kakizaki T, Roppongi RT, Yamazaki H, Yanagawa Y, et al. Low accumulation of drebrin at glutamatergic postsynaptic sites on GABAergic neurons. Neuroscience. 2010;169:1489-500.

30. Miyata S, Kurachi M, Okano Y, Sakurai N, Kobayashi A, Harada K, et al. Blood transcriptomic markers in patients with late-onset major depressive disorder. PLoS ONE. 2016;1 1:e0150262.

31. Kakizaki T, Oriuchi N, Yanagawa Y. GAD65/GAD67 double knockout mice exhibit intermediate severity in both cleft palate and omphalocele compared with GAD67 knockout and VGAT knockout mice. Neuroscience. 2015;288:86-93.

32. Tamamaki N, Yanagawa Y, Tomioka R, Miyazaki Jl, Obata K, Kaneko T. Green fluorescent protein expression and colocalization with calretinin, parvalbumin, and somatostatin in the GAD67-GFP knock-in mouse. J Comp Neurol. 2003;467:60-79.

33. Prut $L$, Belzung C. The open field as a paradigm to measure the effects of drugs on anxiety-like behaviors: a review. Eur J Pharmacol. 2003;463:3-33.

34. Braff DL, Geyer MA, Swerdlow NR. Human studies of prepulse inhibition of startle: normal subjects, patient groups, and pharmacological studies. Psychopharmacology. 2001;156:234-58.

35. Kuwana S, Okada Y, Sugawara Y, Tsunekawa N, Obata K. Disturbance of neural respiratory control in neonatal mice lacking gaba synthesizing enzyme 67-kda isoform of glutamic acid decarboxylase. Neuroscience. 2003;120:861-70.

36. Stork O, Ji F-Y, Kaneko K, Stork S, Yoshinobu Y, Moriya T, et al. Postnatal development of a GABA deficit and disturbance of neural functions in mice lacking GAD65. Brain Res. 2000;865:45-58.
37. Kolata SM, Nakao K, Jeevakumar V, Farmer-Alroth EL, Fujita Y, Bartley AF, et al. Neuropsychiatric phenotypes produced by GABA reduction in mouse cortex and hippocampus. Neuropsychopharmacology. 2018:43:1445-56.

38. Yeomans JS, Frankland PW. The acoustic startle reflex: neurons and connections. Brain Res Rev. 1995;21:301-14.

39. Burianova J, Ouda L, Profant O, Syka J. Age-related changes in GAD levels in the central auditory system of the rat. Exp Gerontol. 2009;44:161-9.

40. Turner JG, Parrish JL, Zuiderveld L, Darr S, Hughes LF, Caspary DM, et al. Acoustic experience alters the aged auditory system. Ear Hear. 2013;34:151-9.

41. Ito T, Inoue K, Takada M. Distribution of glutamatergic, GABAergic, and glycinergic neurons in the auditory pathways of macaque monkeys. Neuroscience. 2015;310:128-51.

42. Uchida T, Oki Y, Yanagawa Y, Fukuda A. A heterozygous deletion in the glutamate decarboxylase 67 gene enhances maternal and fetal stress vulnerability. Neurosci Res. 2011;69:276-82.

43. Chekmareva NY, Umriukhin AE, Landgraf R, Sotnikov SV. Inborn vs acquired anxiety in cross-breeding and cross-fostering $H A B / L A B$ mice bred for extremes in anxiety-related behavior. Behav Neurosci. 2019;133:68-76.

44. Cherlyn SYT, Woon PS, Liu JJ, Ong WY, Tsai GC, Sim K. Genetic association studies of glutamate, GABA and related genes in schizophrenia and bipolar disorder: a decade of advance. Neurosci Biobehav Rev. 2010:34:958-77.

45. Lacerda-Pinheiro SF, Pinheiro Junior RFF, De Lima MAP, Da Silva CGL, Dos Santos MDSV, Teixeira Júnior AG, et al. Are there depression and anxiety genetic markers and mutations? A systematic review. J Affect Disord. 2014;168:387-98.

46. Mitchell AC, Jiang Y, Peter C, Akbarian S. Transcriptional regulation of GAD1 GABA synthesis gene in the prefrontal cortex of subjects with schizophrenia. Schizophr Res. 2015;167:28-34.

47. Hashimoto T, Volk DW, Eggan SM, Mirnics K, Pierri JN, Sun Z, et al. Gene expression deficits in a subclass of GABA neurons in the prefrontal cortex of subjects with schizophrenia. J Neurosci. 2003;23:6315-26.

48. Curley AA, Arion D, Volk DW, Asafu-Adjei JK, Sampson AR, Fish KN, et al. Cortical deficits of glutamic acid decarboxylase 67 expression in schizophrenia: clinical, protein, and cell type-specific features. Am J Psychiatry. 2011;168:921-9.

49. Kimoto S, Zaki MM, Holly Bazmi H, Lewis DA. Altered Markers of cortical $\gamma$-aminobutyric acid neuronal activity in schizophrenia role of the NARP gene. JAMA Psychiatry. 2015;72:747-56.

50. Brown JA, Ramikie TS, Schmidt MJ, Báldi R, Garbett K, Everheart MG, et al. Inhibition of parvalbumin-expressing interneurons results in complex behavioral changes. Mol Psychiatry. 2015;20:1499-507.

51. Georgiev D, Yoshihara T, Kawabata R, Matsubara T, Tsubomoto M, Minabe $Y$, et al. Cortical gene expression after a conditional knockout of $67 \mathrm{kda}$ glutamic acid decarboxylase in parvalbumin neurons. Schizophr Bull. 2016:42:992-1002.

\section{Publisher's Note}

Springer Nature remains neutral with regard to jurisdictional claims in published maps and institutional affiliations.

Ready to submit your research? Choose BMC and benefit from:

- fast, convenient online submission

- thorough peer review by experienced researchers in your field

- rapid publication on acceptance

- support for research data, including large and complex data types

- gold Open Access which fosters wider collaboration and increased citations

- maximum visibility for your research: over $100 \mathrm{M}$ website views per year

At BMC, research is always in progress.

Learn more biomedcentral.com/submissions 